\title{
Racine's Andromaque. Absences and Displacements, Edited by N. HAMMOND, J. HARRIS
}

\section{Monica Pavesio}

\section{(2) OpenEdition}

\section{Journals}

\section{Edizione digitale}

URL: https://journals.openedition.org/studifrancesi/43833

DOI: 10.4000/studifrancesi.43833

ISSN: 2421-5856

\section{Editore}

Rosenberg \& Sellier

\section{Edizione cartacea}

Data di pubblicazione: 1 juin 2021

Paginazione: 213-214

ISSN: 0039-2944

\section{Notizia bibliografica digitale}

Monica Pavesio, «Racine's Andromaque. Absences and Displacements, Edited by N. HAMmond, J. HARRIS», Studi Francesi [Online], 193 (LXV | I) | 2021, online dal 01 juillet 2021, consultato il 15 octobre 2022. URL: http://journals.openedition.org/studifrancesi/43833; DOI: https://doi.org/10.4000/studifrancesi. 43833

Questo documento è stato generato automaticamente il 15 octobre 2022

\section{(c) (i) (9)}

Creative Commons - Attribuzione - Non commerciale - Non opere derivate 4.0 Internazionale - CC BY NC-ND 4.0

https://creativecommons.org/licenses/by-nc-nd/4.0/ 


\title{
Racine's Andromaque. Absences and Displacements, Edited by N. HAMMOND,
}

\section{J. HARRIS}

\author{
Monica Pavesio
}

\section{NOTIZIA}

Racine's Andromaque. Absences and Displacements, Edited by N. HAMMOND, J. HARRIS, Leiden/ Boston, Brill Rodopi, 2019, «Etudes de langue et littérature française» 436, 170 pp.

1 Il volume trae origine da una conferenza organizzata a Londra nel 2017, in occasione del 350 anniversario della prima rappresentazione teatrale dell'Andromaque di Racine, avvenuta nel novembre del 1667.

2 Come illustrano i curatori nell'Introduzione, le due tematiche affrontate nei nove contributi che compongono la miscellanea sono direttamente collegate al finale del terzo atto della tragedia di Racine, ossia al momento in cui Andromaca, in preda al dubbio se sposare Pirro o consegnare suo figlio Astianatte ai Greci, abbandona la scena per andare a consultare il suo defunto marito: «Allons, sur son tombeau, consulter mon époux». Nell'atto successivo, rientrerà in scena e deciderà risolutamente di sposare il re dell'Epiro. La tomba di Ettore, invocata in questo verso dell'Andromaque, è il punto di partenza delle riflessioni sviluppatesi durante la conferenza del 2017. Essa, come emerge dall'Introduzione al volume, è, infatti, direttamente collegata alle due tematiche - le assenze e gli spostamenti - che saranno indagate nella pièce di Racine. Assenza: perché il corpo di Ettore non può trovarsi in Epiro, e quindi Andromaca consulterà, presumibilmente, il marito morto su una tomba vuota; spostamento: perché Andromaca esce di scena per consultare Ettore, valicando le barriere dello spazio e del tempo, per consultare l'ombra di un marito morto, il cui corpo è fisicamente assente.

Partendo da queste constatazioni, il volume si propone, come dicevamo, di esplorare il tema delle assenze, che pervade, come si sa, la tragedia, e quello degli spostamenti, 
perché la tragedia è ricca di personaggi che si spostano o che si sono spostati per recarsi in Epiro e di legami tra i personaggi stessi, come la famosa catena degli amori che lega Oreste, Ermione, Pirro, Andromaca e Ettore.

4 I primi tre studi sono dedicati alle assenze nell'Andromaque. NICHOLAS HAMmOND (“Andromaque"'s Absences, pp. 9-23), illustra come l'assenza delle figure chiave di Ettore, Achille, padre di Pirro, e di Elena madre di Ermione, eserciti una forte presa simbolica sui personaggi presenti in scena che, in quanto sopravvissuti, definiscono la loro presenza in relazione ai membri assenti della loro famiglia. Il successivo studio di MICHAEL MORIARTY (Actions and Transactions in "Andromaque", pp. 24-43) affronta il tema della sostituzione nella pièce ed analizza come i principali personaggi cerchino di risolvere i conflitti, offrendo sé stessi come sostituti o altre persone come sostituti di sé stessi. Nell'ultimo contributo (Misrecognitions and Misperceptions in "Andromaque", pp. 44-60), JOSEPH HARRIS analizza un cospicuo numero di falsi riconoscimenti genuini o finti, momenti in cui i personaggi vedono persone non fisicamente presenti o fingono di averle viste.

5 La seconda sezione è incentrata sulle varie forme di ambiguità e ambivalenza in Andromaque, relativamente ai due temi dell'amore e della morte. Il primo contributo di EMILIA Wilton-GOdberfFoRde (Memories, Fantasies, and Realities of Death in Racine's "Andromaque", pp. 61-78) illustra i vari modi in cui il tema della morte affiora nella tragedia, non solo come una realtà incontrovertibile, ma simultaneamente come immaginazione, minaccia, metafora, prospettiva, seguendo una serie di opposizioni tematiche binarie con il concetto di vita raffigurato come sfuggente. Similmente, lo studio di JENNIFER TAMAS (Overcoming the Shadow: "Andromaque"'s Ambivalent Triumph, pp. 95-113) è incentrato sulla simbolica preservazione della morte in vita, ossia sulla vedovanza, e sulle problematiche che affronta Racine nel portare in scena una protagonista vedova. Anche DELPHINE CALLE ("Andromaque" or the Desire to Be Loved, pp. 79-94) inserisce Andromaque nel contesto religioso, rileggendo la tragedia degli amori non corrisposti nell'ottica delle riflessioni agostiniane sull'amour propre ed individuando, nella pièce, una tensione tra differenti concezioni agostiniane dell'amore.

L'ultima sezione si focalizza sugli spostamenti della tragedia nel tempo e nello spazio, con particolare attenzione alle traduzioni e riscritture. MICHAEL HAWCROFT (Translating Liminality: Entrances and Exits in "Andromaque" since 1667, pp. 114-132) illustra come i movimenti scenici presenti nella tragedia siano stati alterati in ben undici traduzioni o adattamenti inglesi dell'Andromaque. KATHERINE IBBETT ("Andromaque" Translated: John Crowne's Racine and the Refugee, pp. 133-146) si sofferma sul primo adattamento inglese del 1675 , rileggendola alla luce delle complesse relazioni geopolitiche e di potere tra Francia e Inghilterra e sulla crisi contemporanea dei rifugiati Ugonotti in terra inglese. L'ultimo saggio di RICHARD PARIS ("Principessa Infelice!". "Andromaque" in Italian Opera to 1819, pp. 146-166), incentrato sull'analisi di un corpus di "opere serie" italiane del Settecento adattate dall'Andromaque, esplora i vari modi in cui la tragedia è stata trasformata per adattarsi ad un nuovo genere. Il volume si conclude con un indice dei nomi. 